\title{
Effects of carbon nanotubes on intercellular communication and involvement of IL-1 genes
}

\author{
Yke Jildouw Arnoldussen $^{1}$ • Kristine Haugen Anmarkrud ${ }^{1}$ • Vidar Skaug ${ }^{1}$. \\ Ron N. Apte ${ }^{2}$ • Aage Haugen ${ }^{1} \cdot$ Shanbeh Zienolddiny ${ }^{1}$
}

Received: 14 December 2015 / Accepted: 16 April 2016/Published online: 21 April 2016

(C) The Author(s) 2016. This article is published with open access at Springerlink.com

\begin{abstract}
An increasing amount of products containing engineered nanoparticles is emerging. Among these particles are carbon nanotubes (CNTs) which are of interest for a wide range of industrial and biomedical applications. There have been raised concerns over the effects of CNTs on human health. Some types of CNTs are classified as group 2B carcinogens by the International Agency for Research on Cancer. CNTs may also induce pulmonary inflammatory and fibrotic effects. By utilizing CNTs of different lengths, we investigated the role of the proinflammatory cytokine, interleukin-1 (IL-1) on gap junctional intercellular communication (GJIC) by using IL-1 wild-type (IL1-WT) and IL-1 knock-out (IL1$\mathrm{KO})$ cells. GJIC decreased equally in both cell types after CNT exposure. Immunofluorescence staining showed Gja1 and Gjb2 in gap junctions and hemichannels for both cell types. Gjb1 and Gjb2 expression was low in IL1-KO cells, which was confirmed by protein analysis. Gjal was upregulated with both CNTs, whereas Gjb1 was down-regulated by CNT-2 in IL1-WT cells. Connexin mRNA expression was regulated differently by the CNTs. CNT-1 affected Gjal and Gjb2, whereas CNT-2 had an effect on Gjb1. CNTs negatively affect GJIC through gap junctions independently of the length
\end{abstract}

Electronic supplementary material The online version of this article (doi:10.1007/s12079-016-0323-0) contains supplementary material, which is available to authorized users.

Shanbeh Zienolddiny

shan.zienolddiny@stami.no

1 Department of Biological and Chemical Work Environment, National Institute of Occupational Health, Pb 8149 Dep, N-0033 Oslo, Norway

2 The Shraga Segal Department of Microbiology, Immunology and Genetics, The Faculty of Health Sciences, Ben Gurion University of the Negev, 84105 Beer Sheva, Israel of CNT and IL-1 status. Furthermore, connexin gene expression was affected by IL-1 at transcriptional and translational levels. As both CNTs used in this study are cytotoxic to the cells and reduce cell survival, we suggest that CNT-induced reduction in GJIC may be important for inhibiting transfer of cell survival signals between cells.

Keywords Intercellular communication · Connexins · CNT • IL-1

\section{Background}

There is increased focus on the potential negative health effects of exposure to manufactured carbon nanotubes (CNTs). The production and use of CNTs has extensively increased followed by potential health concerns for both work force and consumers (Dong and Ma 2015, Lee et al. 2015). The physico-chemical properties of CNTs such as fibrous structure, high aspect ratio, rigidity and bio-durability are important for the observed inflammagenic, fibrotic and tumorigenic effects (Donaldson et al. 2006, Donaldson et al. 2013, Grosse et al. 2014). In addition, the great structural resemblance to asbestos has significantly increased the focus of understanding the molecular mechanisms underlying the toxicity induced by CNTs (Donaldson et al. 2013).

Inflammation and various signaling pathways may be important for communication between cells (Zhou and Jiang 2014). Intercellular communication is mediated by connexins which are proteins that form hemichannels and gap junction channels between cells. Whereas hemichannels are important for sampling of the extracellular milieu, the gap junction channels are necessary for direct intercellular communication. During the formation of an intercellular channel, six connexin proteins oligomerize into a hemichannel (connexon) and after 
docking to another hemichannel in an opposing cell the intact channel is formed. Gap junction channels mediate the diffusion of several small and hydrophilic substances including adenosine triphosphate, cyclic adenosine monophosphate, inositol triphosphate, glutathione, glutamate, glucose and several ions between cells (Alexander and Goldberg 2003). Thus far, 21 and 20 different types of connexins have been discovered in humans and mice, respectively, and the permeability and signaling properties of the gap junctions is determined by the specific connexins present (Zhou and Jiang 2014). Gap junctions allow for the transfer of small molecules between adjoining cells and many physiological cellular processes such as proliferation, cell growth and apoptosis are dependent on the transfer through these channels (Alexander and Goldberg 2003, Decrock et al. 2009). Intercellular communication through gap junctions is tightly controlled through rapid dynamic formation and degradation of the gap junctions in response to various types of stimuli including changes in voltage, $\mathrm{pH}$ or phosphorylation of connexins (Beardslee et al. 1998, Herve et al. 2007, Lampe and Lau 2004, Falk et al. 2009, Gaietta et al. 2002).

There are only a few studies investigating dysregulation of gap junction intercellular communication (GJIC) as a mechanism of nanoparticle toxicity. In human mesenchymal stem cells the regulation of gap junctions was important for cytotoxicity of quantum dots (Chang et al. 2009). In co-culture of cardiac cells and mesenchymal stem cells, the establishment of GJIC between the two cell types was increased by iron oxide nanoparticles that significantly increased expression of connexin 43 (Cx43) (Han et al. 2015). In human lung A549 cells silver nanoparticles increased GJIC through upregulation of $\mathrm{Cx} 43$ protein expression (Deng et al. 2010). Loss of GJIC and delocalization of $\mathrm{Cx} 43$ were observed in rat lung epithelial cells exposed to carbon black and silica nanoparticles (Ale-Agha et al. 2010).

CNT exposure of rodents induces inflammation, formation of granulomas and fibrosis (Poland et al. 2008, Porter et al. 2013, Porter et al. 2010, Dong et al. 2015). A recent study showed that elevated expression of the proinflammatory cytokines tumor necrosis factor- $\alpha$ (TNF- $\alpha$ ), interleukin- $1 \alpha$ (IL-1 $\alpha)$, IL-1 $\beta$, IL-6 and chemokine (C-C motif) ligand 2 (CCL-2) in lung tissues as well as bronchoalveolar lavage from mice exposed to CNTs may play a role (Dong et al. 2015).

Although there is increasing evidence on the role of inflammation in CNT-induced toxicity, fibrogenesis and tumorigenesis (Dong and Ma 2015), the molecular mechanisms remain unknown. A correlation between connexin expression, GJIC and IL-1 proinflammatory cytokines has been reported. For example, treatment of rat astrocytes with a mixture of IL-1 $\beta$ and TNF- $\alpha$ resulted in a reduction in the total and cell surface levels of $\mathrm{Cx} 43$ and GJIC (Retamal et al. 2007). These data indicate that regulation of GJIC and connexins depends on the type of nanoparticle, the cell type, and that inflammatory cytokines have a role in this regulation. We have previously investigated the effect of two different CNTs on cellular toxicity including doses from $0.02 \mu \mathrm{g} / \mathrm{ml}$ up to $100 \mu \mathrm{g} / \mathrm{ml}$ (Arnoldussen et al. 2015). The same study showed that CNTs affect several cellular responses and that the IL-1 proinflammatory cytokines may be involved in this (Arnoldussen et al. 2015). Of specific interest was $I L-1 \alpha$ that was upregulated after CNT exposure (Arnoldussen et al. 2015). Furthermore, a downregulation of precursor IL- $1 \alpha$ after $24 \mathrm{~h}$ of CNT exposure coincided with a reduction in activated c-Jun $\mathrm{N}$-terminal kinase (JNK) of which IL-1 $\alpha$ is an activator. Other studies have shown the importance of GJIC and Cx43 in controlling cell survival and apoptosis (Gilleron et al. 2009, Tekpli et al. 2010). As inflammation, cell survival and apoptosis are linked together after CNT exposure, it was of interest to investigate if GJIC could play a role in these processes. We hypothesized that one of the mechanisms for the CNT effects is through interference with gap junctional intercellular communication in addition to dysregulation of connexin expression. The objective of this study was to investigate i) if CNTs affect intercellular communication ii) if the response of cells to CNTs depends on IL-1 signaling by investigating differences in GJIC in the presence or absence of IL-1 genes.

\section{Materials and methods}

\section{Cells and cell culture conditions}

IL- $1 \alpha / \beta$ wild type (IL1-WT) and IL- $1 \alpha / \beta$ double knock-out (IL1-KO) cell lines were previously described (Arnoldussen et al. 2015, Krelin et al. 2007, Voronov et al. 2010). Briefly, these fibrosarcoma cell lines were derived from 3 methylcholanthrene-induced tumors that were recovered from IL1-WT and IL1-KO BALB/c mice three months after injection of the carcinogen. The same conditions as before were used and passage numbers were kept between 20 and 30. Cells were routinely kept in a humidified $5 \% \mathrm{CO}_{2}$ and $95 \%$ air incubator at $37^{\circ} \mathrm{C}$ in Dulbecco's Modified Eagle's Medium (DMEM, Sigma-Aldrich) containing $10 \%$ fetal bovine serum (FBS, Biochrom), $50 \mathrm{U} / \mathrm{ml}$ penicillin and $50 \mu \mathrm{g} / \mathrm{ml}$ streptomycin (Thermo Scientific).

\section{Characterization of the carbon nanotubes}

Two multi-walled carbon nanotubes (CNTs) with different lengths and diameters as described earlier (Arnoldussen et al. 2015) were used; CNT-1 (Mitsui-7 lot \#061,220-24) consisted of mainly long fibers (mean length $=5000 \mathrm{~nm}$ and mean diameter $=62 \mathrm{~nm}$ ), CNT-2 consisted of mainly short fibers (mean length $=900 \mathrm{~nm}$ and mean diameter $=31 \mathrm{~nm}$ ). Both CNTs were extensively characterized by SEM, TEM and 
EDX, and the data are published previously (Arnoldussen et al. 2015).

\section{Preparation of CNTs for cell culture experiments}

Weighing and dispersion were performed as previously described (Arnoldussen et al. 2015). Briefly, CNTs were weighed and added to dispersion media (DM; (Porter et al. 2008)) before sonication on ice (Branson probe sonicator, $30 \%$ amplitude pulse cycle, $3 \times 5 \mathrm{~min}$ ) and immediate addition to cell culture media.

\section{Functional assay of GJIC by scrape loading}

GJIC was determined by quantitative scrape loading (Opsahl and Rivedal 2000). IL1-WT and IL1-KO cells were cultured on cover slips in 12-well plates (NUNC) and grown until 80$90 \%$ confluent. The cells were then exposed to $5 \mu \mathrm{g} / \mathrm{ml}$ of CNT-1 and CNT-2 for $24 \mathrm{~h}$. Before scrape loading the confluent cell layer was washed twice with PBS. Then $1 \mathrm{ml}$ of $0.05 \%$ Lucifer Yellow (Sigma-Aldrich) dissolved in PBS w/o Ca ${ }^{2+}$ and $\mathrm{Mg}^{2+}$ was added to each well and the cell monolayer was cut with a surgical scalpel four times. After $4 \mathrm{~min}$ the Lucifer Yellow solution was removed, the well was washed with PBS four times and then cells were fixed in $3.7 \%$ formalin $\mathrm{o} / \mathrm{n}$. The next day the wells were washed with PBS two times before mounting of the cover slips with Mowiol (Calbiochem). Fluorescence was observed using a laser scanning microscope (LSM 710, Zeiss) with a magnification of $20 \times$ and photographs were taken with an AxioCam camera (Zeiss). Ten images were taken for each exposure. Analysis was done by the public domain NIH Image program. The same settings were used for each measurement. The levels of GJIC were analyzed by means of the area of dyecoupled cells.

\section{Intercellular observation of connexin proteins by immunofluorescence (IF)}

IL1-WT and IL1-KO cells were cultured on cover slips and were allowed to attach for $24 \mathrm{~h}$ before exposure to $5 \mu \mathrm{g} / \mathrm{ml}$ of CNT-1 and CNT-2 for $24 \mathrm{~h}$. Cells were then fixed for $20 \mathrm{~min}$ in $4 \%$ paraformaldehyde and permeabilized with $0.1 \%$ Triton $\mathrm{X}-100$ in PBS for $5 \mathrm{~min}$. Cover slips were blocked by incubation with $5 \%$ BSA in $0.1 \%$ PBS-Triton X-100 for $1 \mathrm{~h}$ at room temperature and incubated overnight with a primary antibody against Gjal (rabbit connexin 43 polyclonal antibody, Cell Signaling Technology), Gjb1 (mouse anticonnexin-32 monoclonal antibody, Millipore) or Gjb2 (goat anti-Gjb2 polyclonal antibody, Abcam) in $3 \%$ BSA in PBS at $4{ }^{\circ} \mathrm{C}$ in a humidified chamber. Secondary antibodies antirabbit Alexa Fluor 488, anti-mouse Alexa Fluor 488 or antigoat Alexa Fluor 488 (all from Molecular Probes) were left on the cells for $1 \mathrm{~h}$ at room temperature in a humidified chamber. To visualize cell nuclei cells were counterstained with Hoechst (Sigma-Aldrich). Mowiol was used for mounting of the cover slips. Fluorescence was observed using a laser scanning microscope (LSM 710, Zeiss) and pictures were taken with an AxioCam camera (Zeiss).

\section{Quantitative PCR (qPCR) for measurement of connexin mRNA expression}

mRNA levels of Gja1, Gjb1 and Gjb2 were measured by qPCR. Briefly, total RNA was extracted from IL1-WT and IL1-KO cells using Isol-RNA lysis reagent (5 PRIME) and the obtained RNA was DNase treated with DNA-free ${ }^{\text {TM }}$ DNA Removal Kit (Ambion). cDNA was then made using qScript cDNA synthesis kit (Quanta Biosciences) according to the manufacturers' recommendations. qPCR was performed for Gjal, Gjb1, Gjb2 and $\beta$-actin as a housekeeping gene on a StepOne Real-Time PCR system (Applied Biosystems) with Perfecta SYBR Green FastMix, ROX (Quanta BioSciences). Primer sequences are available upon request. A serial diluted internal standard served as a control for the qPCR reaction. Relative gene expression levels were calculated and normalized to $\beta$-actin.

\section{Western blot analysis for detection of connexin protein expression}

Western blot analysis was performed as described previously (Arnoldussen et al. 2015). Briefly, concentrations of the extracted protein were measured using NanoDrop-8000 (Thermo Scientific). $100 \mu \mathrm{g}$ of protein for each sample was resolved on AnykD Mini protean TGX stain free gels (BioRad) and transferred to a PVDF membrane (Transblot Turbo Transfer pack, Bio-Rad). The Trans-Blot Turbo blotting system (Bio-Rad) was used for transfer. Antibodies used were as follows; Gja1 (rabbit connexin 43 polyclonal antibody, Cell Signaling Technology), Gjb1 (mouse anti-connexin-32 monoclonal antibody, Millipore), Gjb2 (goat anti-Gjb2 polyclonal antibody, Abcam), Sodium Potassium ATPase alpha 1 (mouse anti-NaK ATPase $\alpha 1$ monoclonal antibody, Abcam) and $\alpha$ Tubulin (rabbit monoclonal antibody, Cell Signaling Technology). Horseradish peroxidase HRP-conjugated secondary antibodies against rabbit and mouse (both from Cell Signaling Technology) and against goat (Santa Cruz Biotechnology, INC) were used.

\section{Isolation of integral membrane and membrane-associated proteins}

IL1-WT and IL1-KO cells were exposed to $5 \mu \mathrm{g} / \mathrm{ml}$ of CNT-1 and CNT-2 for $24 \mathrm{~h}$. Cells were then harvested and the MemPER Plus Membrane Protein Kit (ThermoFisher Scientific) 
was used to isolate cytosolic and integral membrane/ membrane-associated proteins into two fractions. The manufacturers' instructions were followed precisely. Protein extracts were then subjected to western blot analysis.

\section{Statistical methods}

Statistical analysis of differences in gene and protein expression was performed using the Student's t-test. $p<0.05$ were considered as statistically significant.

\section{Results}

Two different CNTs, CNT-1 containing long fibers and CNT-2 containing short fibers, were used. IL1-WT and IL1-KO cells were exposed to $5 \mu \mathrm{g} / \mathrm{ml}$ of each of the two CNTs. Among the different doses tested, this dose reduced the cell number for both CNTs used and had an effect on intracellular signaling, as recently shown (Arnoldussen et al. 2015). The cells' morphology changed after CNT exposure including increased detachment and a reduction in cellular adhesion (Suppl. Figure 1). Investigation of GJIC showed that it was significantly higher in IL1-KO cells compared to IL1-WT cells both in the control and CNT exposed cells after $24 \mathrm{~h}$ (Fig. 1; representative images are shown in Suppl. Figure 2A). Furthermore, exposure by CNT-1 and CNT-2 significantly reduced GJIC compared to controls. The fold reduction compared to controls was similar; approximately 1.5 fold (Fig. 1). Similar results were obtained with CNT exposure for 48 h (Suppl. Figure 2B). Thus, exposure to CNTs leads to a decrease in GJIC, but is not dependent on the presence of IL-1 genes.

Localization of Gja1 (Cx43), Gjb1 (Cx32) and Gjb2 (Cx26) in the cells was studied by immunofluorescence (IF) using laser scanning microscopy. This showed specific staining of Gjal in hemichannels and gap junctions for both IL1-WT and IL1-KO cells with or without CNT exposure for $24 \mathrm{~h}$ (Fig. 2a). Gjb1 was increasingly expressed in mitotic cells and was specifically present in the cells' protrusions (Fig. 2b). There was, however, a smaller degree of specific localization to hemichannels and gap junctions than observed for Gjal. In addition, staining was low in IL1-KO cells but was independent of CNT exposure (Fig. 2b). Gjb2 was clearly expressed in hemichannels and gap junctions and to a higher extent in IL1-WT cells than IL1-KO cells (Fig. 2c). Again, exposure to CNTs did not affect localization of Gjb2 protein (Fig. 2c).

To further elucidate GJIC functionality and confirm the IF results, the mRNA expression levels of Gjal, Gjb1 and Gjb2 were investigated. IL1-WT and IL1-KO cells were exposed to $5 \mu \mathrm{g} / \mathrm{ml}$ of each of the two CNTs for 24 and $48 \mathrm{~h}$. Quantification of their mRNA expression levels as measured by qPCR showed that the two CNTs affected Gja1, Gjb1 and Gjb2 differently (Fig. 3 and Suppl. Figure 3). Gjal expression was significantly increased with CNT-1 in IL1-WT cells compared to control IL1WT cells. When comparing IL1-WT and IL1-KO cells, Gjal expression was significantly increased in IL1-KO cells which was independent of CNT exposure (Fig. 3a). CNT-1 did not have a significant effect on Gjb1 mRNA expression (Fig. 3b). For CNT-2 exposure, Gjb1 is significantly reduced for both cell types. Figure 3c shows the results for Gjb2 mRNA expression. CNT-1 significantly downregulates Gjb2 in IL1-KO cells compared to the control whereas there is no difference for CNT-2 (Fig. 3c). Gjb2 expression is significantly increased in IL1-KO cells compared to IL1-WT cells. Thus, the three connexins, Gja1, $G j b 1$ and $G j b 2$, investigated are regulated differently by the two different CNTs and at least the expression of Gjal and Gjb2 is affected by IL-1.

The connexin mRNA expression levels were confirmed by western blot analysis of the respective proteins. Representative western blots are shown in Fig. $4 a$ and $b$ after $24 \mathrm{~h}$ of CNT exposure. Quantification of the protein levels indicates that CNT-1 increases Gja1 protein expression significantly in IL1-WT cells compared to exposed IL1-WT control cells (Fig. 4c). For CNT-2 a significant increase in Gjal is observed for IL1-KO cells compared to the control (Fig. 4d). No significant differences for Gja1 between IL1-WT and IL1KO cells were detected in response to the CNTs (Fig. $4 \mathrm{c}$ and d). Gjb1 expression was significantly downregulated in IL1KO cells compared to IL1-WT cells (Fig. 4c and d). CNT-2 had a greater effect than CNT-1 on Gjb1 as Gjb1 is significantly downregulated in exposed IL1-WT cells compared to IL1-WT control cells (Fig. 4d). Gjb2 expression did not change significantly after CNT exposure (Fig. 4c and d). There was however, a significant downregulation in IL1-KO cells compared to IL1-WT (Fig. 4c and d). Whereas Gja1 expression reduced after $48 \mathrm{~h}$ compared to $24 \mathrm{~h}$ of exposure (Suppl. Figure 4), Gjb1 and Gjb2 expression did not differ discernibly from the $24 \mathrm{~h}$ timepoint (Suppl. Figure 4).

As the IF data indicated different localization of the connexins (Fig. 2), fractions containing cytosolic proteins or integrated membrane/membrane-associated proteins were obtained after $24 \mathrm{~h}$ of CNT exposure. Western blot analysis showed an increase of Gja1 in the membrane of IL1-WT cells after CNT-1 exposure (Fig. 5). Furthermore, Gja1 expression increased in the membrane of IL1-KO cells with CNT-2. Gjb1 was present in the cytosolic fractions (Fig. 5). Gjb2 was increasingly expressed in the membrane fractions and to a higher extent in IL1-WT cells than IL1-KO cells. Altogether, these findings show that connexins are regulated at the protein level and that IL-1 has a role in this.

\section{Discussion}

Gap junctions and GJIC play an important role in maintaining cellular homeostasis and to communicate processes involved 


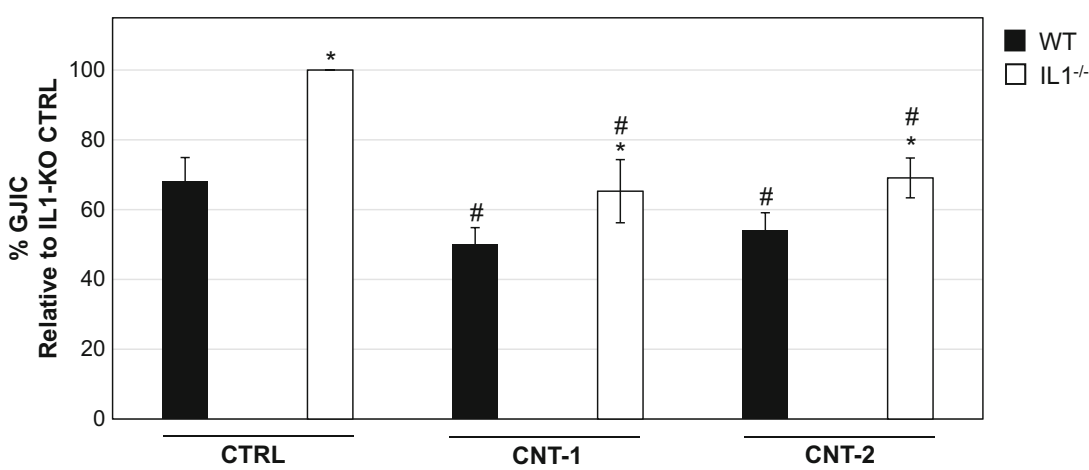

Fig. 1 GJIC decreases in IL1-WT and IL1-KO cells after exposure to CNTs. IL1-WT and IL1-KO cells were grown on coverslips and exposed to dispersion media alone as a control or to $5 \mu \mathrm{g} / \mathrm{ml}$ of CNT- 1 and CNT-2 for $24 \mathrm{~h}$. After this time scrape loading was performed using Lucifer Yellow. Confocal microscopy was used to detect fluorescence and the levels of GJIC were determined by means of the area of dye-coupled cells. Quantification of three independent experiments is shown where the values represent the mean \pm standard error (SE). ${ }^{*} P<0.05$ between IL1-WT and IL1-KO cells. ${ }^{\#} P<0.05$ between exposed IL1-WT or IL1$\mathrm{KO}$ and their respective non-exposed controls in cell growth, differentiation, cell survival and apoptosis. As nanoparticles affect many of these processes it was of interest to investigate GJIC in response to CNTs and how three different connexins are regulated in IL1-WT and IL1-KO cells after exposure to CNTs.

The CNTs used in this study both have a negative effect on GJIC. We have previously shown that the two CNTs with different physico-chemical properties had different effects on cells (Arnoldussen et al. 2015). We found that CNT-1 had a much greater toxicological potential than CNT-2. This was
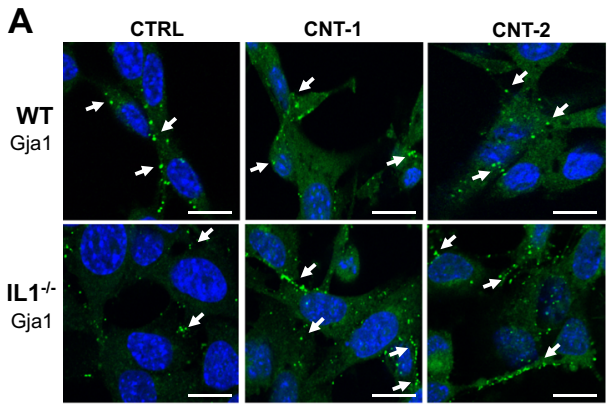

C

CTRL
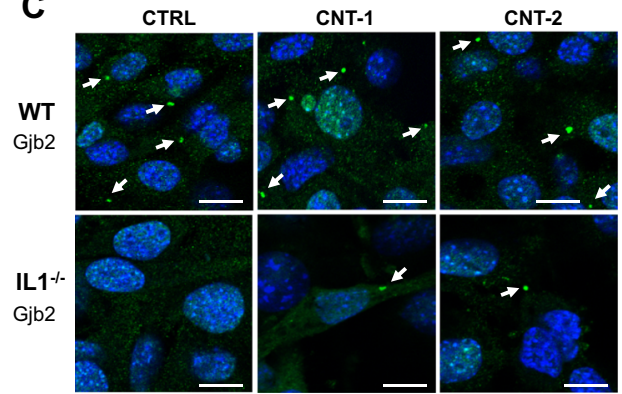

Fig. 2 Immunofluorescence images of Gja1, Gjb1 and Gjb2 in IL1-WT and IL1-KO cells after exposure to CNT-1 and CNT-2. IL1-WT and IL1$\mathrm{KO}$ cells were plated on cover slips and were allowed to attach for $24 \mathrm{~h}$ before exposure to CNTs or dispersion media alone for $24 \mathrm{~h}$. Cells were stained with the respective antibodies and fluorescent secondary antibodies were used to detect expression. Hoechst staining was used to supported by studies showing that short well-dispersed CNTs such as CNT-2, are less cytotoxic to cells, whereas more agglomerated and tangled longer CNTs such as CNT-1 induced more severe levels of cytotoxicity (Wick et al. 2007, Hamilton et al. 2013). It was therefore surprising to find that the two different CNTs alter GJIC similarly (Fig. 1). The results suggest that CNTs have a negative effect on GJIC by having a direct effect on the outer cell membrane, and that this is independent of their characteristics and induction of intracellular signaling pathways. Notion should be taken that a

B

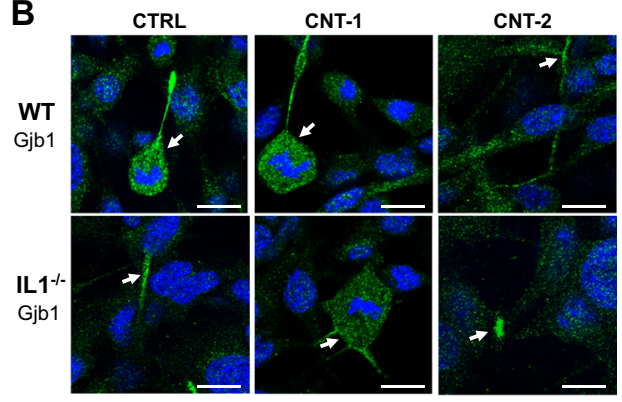

visualize cell nuclei. a Representative images for Gja1. b Representative images for Gjb1. c Representative images for Gjb2. Arrows indicate interesting areas with hemichannels and gap junction channels when present between cells. For Gjb1 arrows also point to dividing cells having increased expression of Gjb1. Scale bar: $10 \mu \mathrm{m}$ 

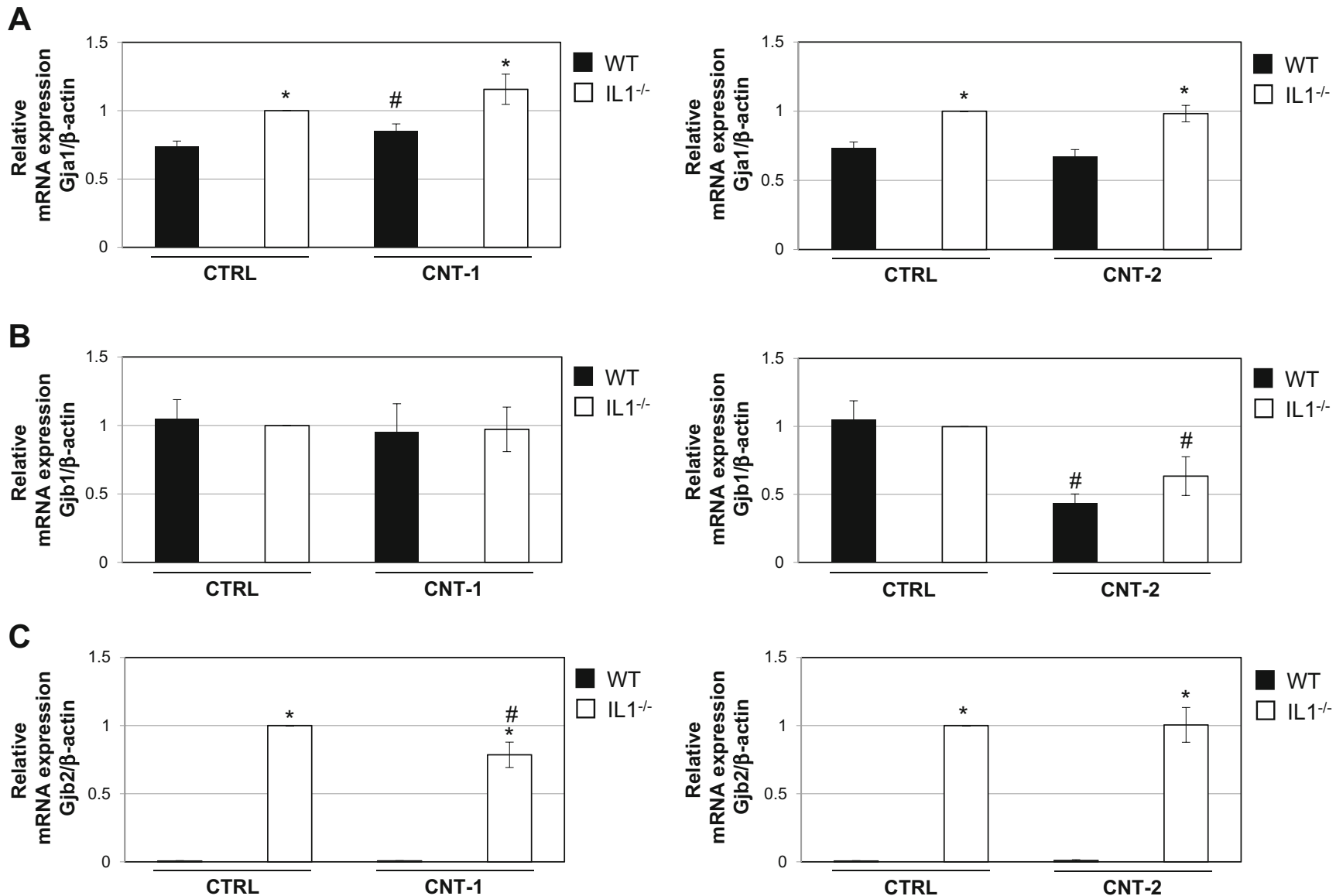

Fig. 3 Gjal, Gjb1 and Gjb2 mRNA expression levels in IL1-WT or IL1$\mathrm{KO}$ cells after exposure to dispersion media alone, CNT-1 or CNT-2. a Gjal mRNA expression levels investigated by qPCR after exposure to CNT-1 and CNT-2 for 24 h. b Gjbl mRNA expression levels after exposure to the CNTs for $24 \mathrm{~h}$. c Gjb2 mRNA expression levels after

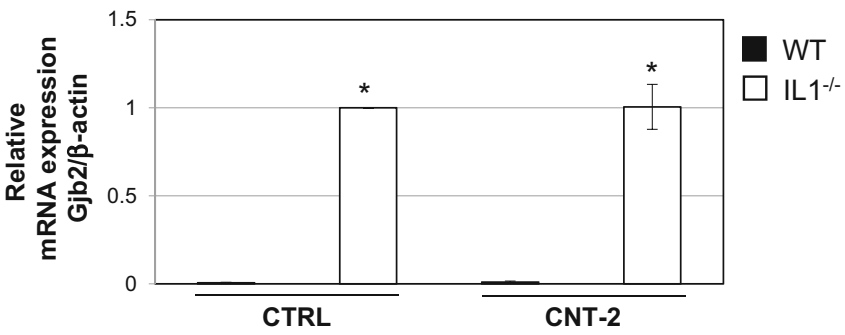

exposure to the CNTs for $24 \mathrm{~h}$. Values represent the mean \pm standard error (SE) of three independent experiments performed in triplicate. $* P<0.05$ between IL1-WT and IL1-KO cells. ${ }^{*} P<0.05$ between exposed IL1-WT or IL1-KO and their respective non-exposed controls

control experiment including cells treated with a gap junction coupling inhibitor to eliminate the bias of cells absorbing the dye during the process of scraping, was not included. Loss of GJIC has been observed in a few other studies after particle exposure. For example, one study found that exposure of rat lung epithelial cells to carbon black and silica particles induced loss of GJIC and delocalization of $\mathrm{Cx} 43$ (Ale-Agha et al. 2010). Furthermore, in rat liver cells, inhibition of GJIC and autophagy were involved in cadmium-induced apoptosis (Zou et al. 2015). These studies have further shown that $\mathrm{Cx} 43$ is responsible for the decrease in GJIC. However, they did not compare two types of the same particle having different physico-chemical properties. The levels of apoptosis were low, approximately $1 \%$ in IL1-WT cells after exposure to CNT-1 or CNT-2 (Arnoldussen et al. 2015). However, IL1KO cells were more robust and had a reduction of 5- and 3fold in the number of cells undergoing apoptosis after exposure to CNT-1 and CNT-2, respectively, compared to IL1-WT cells after $24 \mathrm{~h}$. This may reflect the higher levels of GJIC in IL1-KO cells, which may give increased transfer of cell survival signals.

To further understand the observed effect of CNTs on GJIC, we investigated the protein expression levels of Gja1, Gjb1 and Gjb2 by IF and western blot analysis. Only Gjb1 was significantly downregulated by CNT-2 and may therefore be part of the decrease observed for GJIC. Gjb2 was present both in hemichannels and gap junctions, but its expression levels were not affected by the CNTs. The permeability of Gjb2 channels is low (Goldberg et al. 2004) and may therefore not have an impact on the decrease in GJIC. Of the three connexins investigated, we observed the highest expression of Gjal in hemichannels and gap junctions and it is increased, specifically in the cell membrane, after exposure to both CNTs. This does, however, not explain the reduction in GJIC after CNT exposure and other regulatory mechanisms may exist. The short half-life of connexins aids in their highly regulated function and is determined by several events such as phosphorylation, ubiquitylation and sumoylation. For most cell types phosphorylation and ubiquitylation of $\mathrm{Cx} 43$ is a signal for its internalization and degradation (Falk et al. 2009, Kjenseth et al. 2010, Leithe et al. 2012, Leithe et al. 2006, Lichtenstein et al. 2011). It is known that connexins 

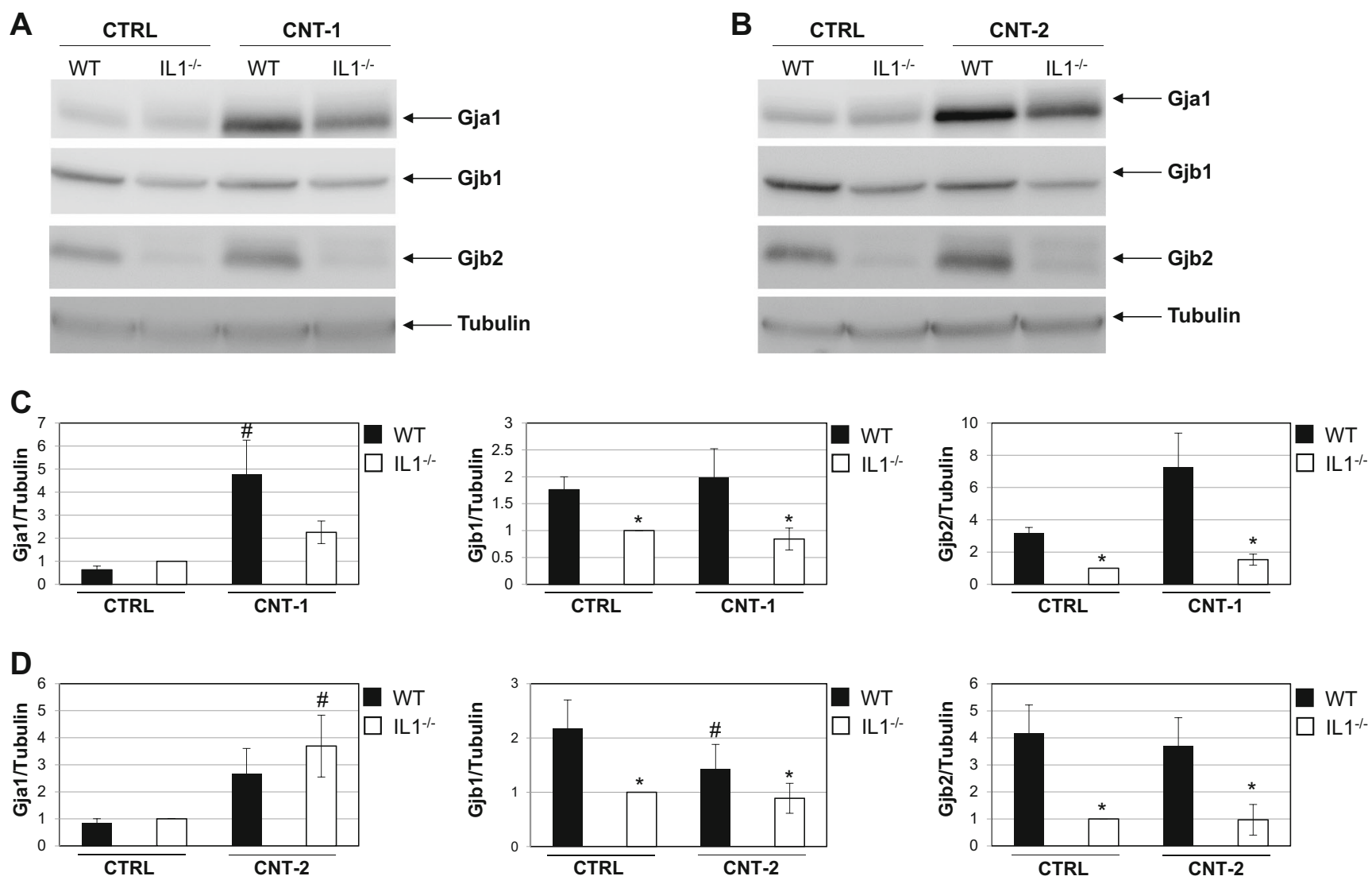

Fig. 4 Gja1, Gjb1 and Gjb2 protein levels in IL1-WT or IL1-KO cells after exposure to dispersion media alone, CNT-1 or CNT-2. a Representative western blots for Gja1, Gjb1 and Gjb2 after exposure to CNT-1. b Representative western blots for Gja1, Gjb1 and Gjb2 after exposure to CNT-2. Tubulin was used as a loading control. c Quantification of Gja1, Gjb1 and Gjb2 protein levels normalized to

tubulin after exposure to CNT-1. d Quantification after exposure to CNT-2. For the bar graphs the values represent the mean \pm standard error (SE) of three independent experiments. ${ }^{*} P<0.05$ between IL1WT and IL1-KO cells. ${ }^{\#} P<0.05$ between exposed IL1-WT or IL1-KO and their respective non-exposed controls

form homomeric or heteromeric gap junction channels that typically affect their selective permeability (Goldberg et al. 2004). There is however lack of tools and technologies to distinguish between the different channel types, including determining the functional differences between hemichannels and gap junctions (Bodendiek and Raman 2010, Iyyathurai et al. 2013, Saez and Leybaert 2014, Spray et al. 2006). In addition, there is an emerging understanding of the plethora of non-channel dependent actions of connexins in intracellular signaling (Vinken et al. 2012, Zhou and Jiang 2014). Of the 20 types of connexins currently found in mice, only three were tested here and thus there is the possibility that other connexins play a role in GJIC in the cells which then are degraded in response to CNTs to reduce the levels of GJIC.

Our results indicate that IL-1 is not important for the overall effects on GJIC, but that its presence or absence affects the mRNA and protein expression levels of Gja1, Gjb1 and Gjb2. Both Gjb1 and Gjb2 have decreased staining in IL1-KO cells which was confirmed by western blot analysis and for Gjb1 mRNA expression after CNT-2 exposure. However, for all exposures IL1-KO cells had a higher basal level of GJIC than
IL1-WT. As the IF results show very little Gjb1 in hemichannels and gap junctions (Fig. 2) this protein is probably not important for GJIC in IL1-KO cells. Gjb2 was present both in hemichannels and gap junctions, but as its expression level was significantly lower in IL1-KO cells, it may not have a role in increased GJIC in these cells. Gjal mRNA and protein expression increases after CNT exposure for $24 \mathrm{~h}$ followed with a decrease after $48 \mathrm{~h}$. The increase after $24 \mathrm{~h}$ coincides with a decrease in JNK activity especially in the IL1-KO cells after exposure to CNT-1 and CNT-2 (Arnoldussen et al. 2015). Some studies show that the JNK signaling pathway controls Cx43 expression (Kimura and Nishida 2010, Zhang et al. 2013). An increase in Gjal as observed in our study in both IL1-WT and IL1-KO cells, may account for the low activation of JNK at the $24 \mathrm{~h}$ timepoint. TNF $\alpha$ has also been implicated to have a negative effect on $\mathrm{Cx} 43$. It was shown to reduce GJC and $\mathrm{Cx} 43$ levels in corneal fibroblasts which was mediated by the JNK signaling pathway (Kimura and Nishida 2010, Kimura et al. 2013). Furthermore, TNF $\alpha$ inhibited Cx43 gap junctions through JNK activity (Zhang et al. 2015, Zhang et al. 2013). TNF $\alpha$ is not expressed in IL1-KO cells 

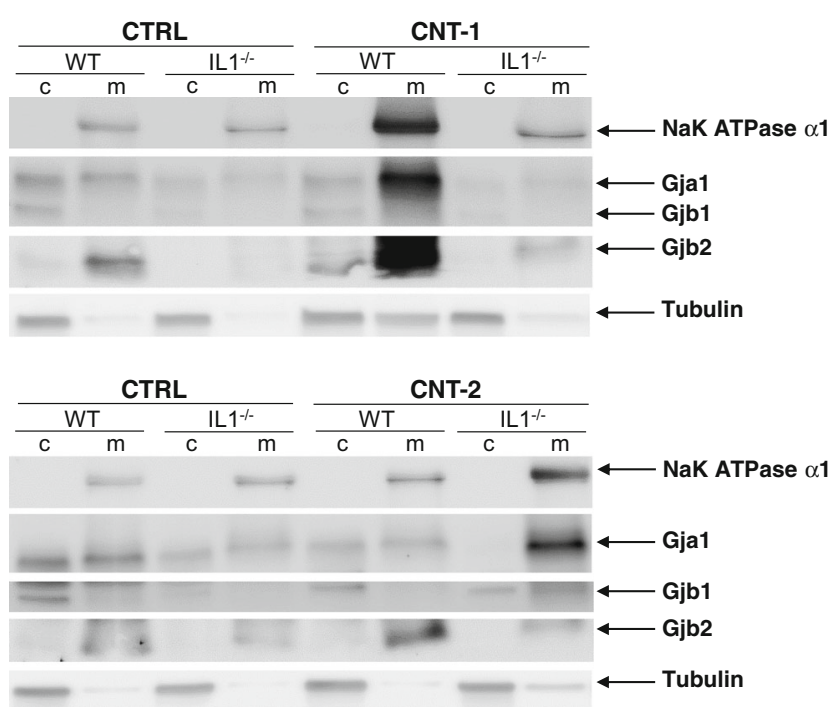

Fig. 5 Localization of Gja1, Gjb1 and Gjb2 protein after CNT exposure. Cytosolic $(c)$ and integral membrane/membrane-associated $(m)$ proteins were separated into two fractions. Western blot analysis was used to investigate the localization of Gja1, Gjb1 and Gjb2. Antibodies against NaK ATPase $\alpha 1$ and $\alpha$-Tubulin were used to detect the membrane and cytosolic fractions, respectively. The images shown are representative of two independent experiments

(Arnoldussen et al. 2015). In these cells, JNK activity is reduced after $24 \mathrm{~h}$ of CNT exposure which coincides with an increase in Gjal levels (Fig. 4). After $48 \mathrm{~h}$ of CNT exposure JNK activity significantly increases (Arnoldussen et al. 2015) concomitant with a reduction in Gja1 (Suppl. Figure 4). Cx43 has been found to directly interact with apoptosis signalregulating 1 (ASK1) which protected against hydrogen peroxide-induced apoptosis in Cx43-overexpressing rat glioma cells (Giardina et al. 2007). As ASK1 is a direct upstream activator of JNK, an increase in Gjal as observed in our study after $24 \mathrm{~h}$ in both IL1-WT and IL1-KO cells, may account for the low activation of JNK through inhibiting ASK1.

$\mathrm{Cx} 43$ has a half-life of between 1.5 and $5 \mathrm{~h}$ (Fallon and Goodenough 1981, Laird et al. 1991) and is prone to a high degree of regulation. There is the probability that the half-life of other connexins is regulated in a similar manner. A limitation of this study is the cell type used, the concentrations of the CNTs and the timepoints used. In this regard these factors may be changed and the effects thereof should be investigated in other cell types. Furthermore, it would be of interest to investigate the effects of mature and secreted IL-1 cytokines on GJIC and connexin expression. In the present study, the levels of protein expression were in many instances different from the mRNA expression levels, especially for Gjb2. Gjb2 was highly expressed in IL1-KO cells and was regulated differently by the CNTs, but low levels of Gjb2 protein were detected in parallel to an increase of Gjb2 in IL1-WT cells. To our knowledge there is no current understanding on the regulation of Gjb2 that could explain these results. However, multiple proteins and other factors may be involved in the regulation of connexins. How changes in these and other pathways influence connexin expression after CNT exposure require further investigation. In conclusion, this is the first study showing that CNTs decrease GJIC independent of their physico-chemical properties. In the cellular response to CNTs the presence or absence of IL-1 does not seem to play an essential role on GJIC.

Acknowledgments Professor Shuji Tsuruoka, University of Nagano, Japan and Mitsui Co., Japan, and Mr. Mogens Mathiesen, former CEO of n-Tec AS, Norway, are acknowledged for the generous gifts of CNT-1 and CNT-2, respectively. We want to thank Dr. Edward Leithe and Ms. Tone Aase Fykerud at the Institute for Cancer Research, Oslo University Hospital, Oslo, Norway for valuable advice and help in establishing the scrapeloading technique. Ms. Mayes Kasem is acknowledged for excellent technical assistance.

\section{Compliance with ethical standards}

Conflict of interest The authors declare "no conflicts of interest". This work was funded mainly by a postdoctoral fellowship to YJA from the Research Council of Norway (NFR 204341/H10) and partly by National Institute of Occupational Heath, Norway.

Open Access This article is distributed under the terms of the Creative Commons Attribution 4.0 International License (http:// creativecommons.org/licenses/by/4.0/), which permits unrestricted use, distribution, and reproduction in any medium, provided you give appropriate credit to the original author(s) and the source, provide a link to the Creative Commons license, and indicate if changes were made.

\section{References}

Ale-Agha N, Albrecht C, Klotz LO (2010) Loss of gap junctional intercellular communication in rat lung epithelial cells exposed to carbon or silica-based nanoparticles. Biol Chem 391:1333-1339

Alexander DB, Goldberg GS (2003) Transfer of biologically important molecules between cells through gap junction channels. Curr Med Chem 10:2045-2058

Arnoldussen YJ, Skogstad A, Skaug V, Kasem M, Haugen A, Benker N, Weinbruch S, Apte RN, Zienolddiny S (2015) Involvement of IL-1 genes in the cellular responses to carbon nanotube exposure. Cytokine 73:128-137

Beardslee MA, Laing JG, Beyer EC, Saffitz JE (1998) Rapid turnover of connexin43 in the adult rat heart. Circ Res 83:629-635

Bodendiek SB, Raman G (2010) Connexin modulators and their potential targets under the magnifying glass. Curr Med Chem 17:4191-4230

Chang JC, Hsu SH, Su HL (2009) The regulation of the gap junction of human mesenchymal stem cells through the internalization of quantum dots. Biomaterials 30:1937-1946

Decrock E, Vinken M, De Vuyst E, Krysko DV, D'Herde K, Vanhaecke T, Vandenabeele P, Rogiers V, Leybaert L (2009) Connexin-related signaling in cell death: to live or let die? Cell Death Differ 16:524-536

Deng F, Olesen P, Foldbjerg R, Dang DA, Guo X, Autrup H (2010) Silver nanoparticles up-regulate Connexin43 expression and increase gap junctional intercellular communication in human lung adenocarcinoma cell line A549. Nanotoxicology 4:186-195

Donaldson K, Aitken R, Tran L, Stone V, Duffin R, Forrest G, Alexander A (2006) Carbon nanotubes: a review of their properties in relation to pulmonary toxicology and workplace safety. Toxicol Sci 92:5-22 
Donaldson K, Poland CA, Murphy FA, MacFarlane M, Chernova T, Schinwald A (2013) Pulmonary toxicity of carbon nanotubes and asbestos - similarities and differences. Adv Drug Deliv Rev 65: 2078-2086

Dong J, Ma Q (2015) Advances in mechanisms and signaling pathways of carbon nanotube toxicity. Nanotoxicology 9:658-676

Dong J, Porter DW, Batteli LA, Wolfarth MG, Richardson DL, Ma Q (2015) Pathologic and molecular profiling of rapid-onset fibrosis and inflammation induced by multi-walled carbon nanotubes. Arch Toxicol 89:621-633

Falk MM, Baker SM, Gumpert AM, Segretain D, Buckheit RW 3rd (2009) Gap junction turnover is achieved by the internalization of small endocytic double-membrane vesicles. Mol Biol Cell 20:3342-3352

Fallon RF, Goodenough DA (1981) Five-hour half-life of mouse liver gap-junction protein. J Cell Biol 90:521-526

Gaietta G, Deerinck TJ, Adams SR, Bouwer J, Tour O, Laird DW, Sosinsky GE, Tsien RY, Ellisman MH (2002) Multicolor and electron microscopic imaging of connexin trafficking. Science 296:503507

Giardina SF, Mikami M, Goubaeva F, Yang J (2007) Connexin 43 confers resistance to hydrogen peroxide-mediated apoptosis. Biochem Biophys Res Commun 362:747-752

Gilleron J, Carette D, Durand P, Pointis G, Segretain D (2009) Connexin 43 a potential regulator of cell proliferation and apoptosis within the seminiferous epithelium. Int J Biochem Cell Biol 41:1381-1390

Goldberg GS, Valiunas V, Brink PR (2004) Selective permeability of gap junction channels. Biochim Biophys Acta 1662:96-101

Grosse Y, Loomis D, Guyton KZ, Lauby-Secretan B, El Ghissassi F, Bouvard V, Benbrahim-Tallaa L, Guha N, Scoccianti C, Mattock $\mathrm{H}$, Straif K, International Agency for Research on Cancer Monograph Working, G (2014) Carcinogenicity of fluoro-edenite, silicon carbide fibres and whiskers, and carbon nanotubes. Lancet Oncol 15:1427-1428

Hamilton RF Jr, Wu Z, Mitra S, Shaw PK, Holian A (2013) Effect of MWCNT size, carboxylation, and purification on in vitro and in vivo toxicity, inflammation and lung pathology. Part Fibre Toxicol 10:57

Han J, Kim B, Shin JY, Ryu S, Noh M, Woo J, Park JS, Lee Y, Lee N, Hyeon T, Choi D, Kim BS (2015) Iron oxide nanoparticle-mediated development of cellular gap junction crosstalk to improve mesenchymal stem cells' therapeutic efficacy for myocardial infarction. ACS Nano 9:2805-2819

Herve JC, Bourmeyster N, Sarrouilhe D, Duffy HS (2007) Gap junctional complexes: from partners to functions. Prog Biophys Mol Biol 94: $29-65$

Iyyathurai J, D'Hondt C, Wang N, De Bock M, Himpens B, Retamal MA, Stehberg J, Leybaert L, Bultynck G (2013) Peptides and peptide-derived molecules targeting the intracellular domains of $\mathrm{Cx} 43$ : gap junctions versus hemichannels. Neuropharmacology 75:491-505

Kimura K, Nishida T (2010) Role of the ubiquitin-proteasome pathway in downregulation of the gap-junction protein Connexin 43 by TNF\{alpha\} in human corneal fibroblasts. Invest Ophthalmol Vis Sci 51:1943-1947

Kimura K, Orita T, Morishige N, Nishida T, Sonoda KH (2013) Role of the JNK signaling pathway in downregulation of connexin43 by TNF-alpha in human corneal fibroblasts. Curr Eye Res 38:926-932

Kjenseth A, Fykerud T, Rivedal E, Leithe E (2010) Regulation of gap junction intercellular communication by the ubiquitin system. Cell Signal 22:1267-1273

Krelin Y, Voronov E, Dotan S, Elkabets M, Reich E, Fogel M, Huszar M, Iwakura Y, Segal S, Dinarello CA, Apte RN (2007) Interleukin1 beta-driven inflammation promotes the development and invasiveness of chemical carcinogen-induced tumors. Cancer Res 67:10621071
Laird DW, Puranam KL, Revel JP (1991) Turnover and phosphorylation dynamics of connexin43 gap junction protein in cultured cardiac myocytes. Biochem J 273(Pt 1):67-72

Lampe PD, Lau AF (2004) The effects of connexin phosphorylation on gap junctional communication. Int J Biochem Cell Biol 36:11711186

Lee JS, Choi YC, Shin JH, Lee JH, Lee Y, Park SY, Baek JE, Park JD, Ahn K, Yu IJ (2015) Health surveillance study of workers who manufacture multi-walled carbon nanotubes. Nanotoxicology 9: 802-811

Leithe E, Sirnes S, Omori Y, Rivedal E (2006) Downregulation of gap junctions in cancer cells. Crit Rev Oncog 12:225-256

Leithe E, Sirnes S, Fykerud T, Kjenseth A, Rivedal E (2012) Endocytosis and post-endocytic sorting of connexins. Biochim Biophys Acta 1818:1870-1879

Lichtenstein A, Minogue PJ, Beyer EC, Berthoud VM (2011) Autophagy: a pathway that contributes to connexin degradation. J Cell Sci 124:910-920

Opsahl H, Rivedal E (2000) Quantitative determination of gap junction intercellular communication by scrape loading and image analysis. Cell Adhes Commun 7:367-375

Poland CA, Duffin R, Kinloch I, Maynard A, Wallace WA, Seaton A, Stone V, Brown S, Macnee W, Donaldson K (2008) Carbon nanotubes introduced into the abdominal cavity of mice show asbestos-like pathogenicity in a pilot study. Nat Nanotechnol $3: 423-428$

Porter D, Sriram K, Wolfarth M, Jefferson A, Schwegler-Berry D, Andrew M, Castranova V (2008) A biocompatible medium for nanoparticle dispersion. Nanotoxicology 2:144-154

Porter DW, Hubbs AF, Mercer RR, Wu N, Wolfarth MG, Sriram K, Leonard S, Battelli L, Schwegler-Berry D, Friend S, Andrew M, Chen BT, Tsuruoka S, Endo M, Castranova V (2010) Mouse pulmonary dose- and time course-responses induced by exposure to multi-walled carbon nanotubes. Toxicology 269:136-147

Porter DW, Hubbs AF, Chen BT, McKinney W, Mercer RR, Wolfarth MG, Battelli L, Wu N, Sriram K, Leonard S, Andrew M, Willard P, Tsuruoka S, Endo M, Tsukada T, Munekane F, Frazer DG, Castranova V (2013) Acute pulmonary doseresponses to inhaled multi-walled carbon nanotubes. Nanotoxicology 7:1179-1194

Retamal MA, Froger N, Palacios-Prado N, Ezan P, Saez PJ, Saez JC, Giaume C (2007) Cx43 hemichannels and gap junction channels in astrocytes are regulated oppositely by proinflammatory cytokines released from activated microglia. J Neurosci 27:13781-13792

Saez JC, Leybaert L (2014) Hunting for connexin hemichannels. FEBS Lett 588:1205-1211

Spray DC, Ye ZC, Ransom BR (2006) Functional connexin "hemichannels": a critical appraisal. Glia 54:758-773

Tekpli X, Rivedal E, Gorria M, Landvik NE, Rissel M, Dimanche-Boitrel MT, Baffet G, Holme JA, Lagadic-Gossmann D (2010) The B[a]Pincreased intercellular communication via translocation of connexin-43 into gap junctions reduces apoptosis. Toxicol Appl Pharmacol 242:231-240

Vinken M, Decrock E, Leybaert L, Bultynck G, Himpens B, Vanhaecke T, Rogiers V (2012) Non-channel functions of connexins in cell growth and cell death. Biochim Biophys Acta 1818:2002-2008

Voronov E, Reich E, Dotan S, Dransh P, Cohen I, Huszar M, Fogel M, Kleinman HK, White RM, Apte RN (2010) Effects of IL-1 molecules on growth patterns of 3-MCA-induced cell lines: an interplay between immunogenicity and invasive potential. J Immunotoxicol 7:27-38

Wick P, Manser P, Limbach LK, Dettlaff-Weglikowska U, Krumeich F, Roth S, Stark WJ, Bruinink A (2007) The degree and kind of agglomeration affect carbon nanotube cytotoxicity. Toxicol Lett 168: $121-131$ 
Zhang FF, Morioka N, Nakashima-Hisaoka K, Nakata Y (2013) Spinal astrocytes stimulated by tumor necrosis factor-alpha and/or interferon-gamma attenuate connexin 43-gap junction via c-jun terminal kinase activity. J Neurosci Res 91:745-756

Zhang FF, Morioka N, Kitamura T, Hisaoka-Nakashima K, Nakata Y (2015) Proinflammatory cytokines downregulate connexin 43-gap junctions via the ubiquitin-proteasome system in rat spinal astrocytes. Biochem Biophys Res Commun 464:1202-1208
Zhou JZ, Jiang JX (2014) Gap junction and hemichannel-independent actions of connexins on cell and tissue functions-an update. FEBS Lett 588:1186-1192

Zou H, Zhuo L, Han T, Hu D, Yang X, Wang Y, Yuan Y, Gu J, Bian J, Liu X, Liu Z (2015) Autophagy and gap junctional intercellular communication inhibition are involved in cadmium-induced apoptosis in rat liver cells. Biochem Biophys Res Commun 459:713-719 